\title{
A Case of suspected Sick Sinus Syndrome due to combined Beta-blocker and Calcium Channel Blocker Therapy: Anesthesia Management
}

\author{
${ }^{1}$ Apeksha A Gala, ${ }^{2}$ Naina P Dalvi, ${ }^{3}$ Sunil K Gvalani, ${ }^{4}$ Sourav Mahajan
}

\begin{abstract}
Sick sinus syndrome (SSS) is a generalized abnormality of cardiac impulse formation. Abnormalities encompassed by this syndrome may include inappropriate sinus bradycardia, sinus arrest, bradyarrhythmias, or tachyarrhythmias. We present a case of a 54-year-old hypertensive male posted for L4-L5 decompression, whom we suspected to develop SSS due to overdose of combined beta-blocker (BB) and calcium channel blocker (CCB) therapy.
\end{abstract}

Keywords: Beta-blocker-calcium channel blocker toxicity, Inotropes, Preanesthesia checkup, Sick sinus syndrome.

How to cite this article: Gala AA, Dalvi NP, Gvalani SK, Mahajan S. A Case of suspected Sick Sinus Syndrome due to combined Beta-blocker and Calcium Channel Blocker Therapy: Anesthesia Management. Res Inno in Anesth 2017;2(2):68-70.

Source of support: Nil

Conflict of interest: None

\section{INTRODUCTION}

Sick sinus syndrome is a generalized abnormality of cardiac impulse formation. Abnormalities encompassed by this syndrome include sinus bradycardia, sinus arrest or exit block, and combination of sinoatrial and atrioventricular nodal conduction disturbances. ${ }^{1,2}$

Beta-blockers and CCBs are the main groups of cardiac drugs in use for several years. Unfortunately, they also remain common causes of cardiovascular collapse following accidental or intentional overdose. Toxicity is associated with significant mortality. ${ }^{3}$

We present a case of a 54-year-old hypertensive male, posted for L4-L5 spine decompression, in whom we suspect BB and CCB toxicity, which manifested as an SSS-like state.

\footnotetext{
${ }^{1}$ Assistant Professor, ${ }^{2}$ Additional Professor, ${ }^{3}$ Professor and Head, ${ }^{4}$ Senior Registrar

${ }^{1-4}$ Department of Anesthesia, Hinduhridaysamrat Balasaheb Thackeray Medical College and Dr. Rustom Narsi Cooper Municipal General Hospital, Mumbai, Maharashtra, India

Corresponding Author: Apeksha A Gala, 47, Jansukh Nivas Kasturba Road, Kandivali (West), Mumbai 400067, Maharashtra India, Phone: +912226208894, e-mail: appi.apeksha@gmail. com
}

\section{CASE REPORT}

A 54-year-old male patient weighing $70 \mathrm{~kg}$ was posted for lumbar spine decompression at L4-L5 level, with instrumentation. Patient was a known hypertensive since 4 years, for which he was on tablet amlodipine and atenolol combination (5-50 mg), once a day, and a known diabetic on injection insulin 4-4-4 subcutaneous. Preoperative investigations were within normal limits. Preoperative pulse was 50/min, sinus rhythm was regular, and blood pressure (BP) 100/70 $\mathrm{mm} \mathrm{Hg}$. Patient was premedicated with injection glycopyrrolate $0.004 \mathrm{mg} / \mathrm{kg}$, injection midazolam $0.05 \mathrm{mg} / \mathrm{kg}$, injection fentanyl $1.5 \mu \mathrm{g} / \mathrm{kg}$ and was induced with injection propofol $2 \mathrm{mg} / \mathrm{kg}$. Ventilation was confirmed and patient was administered injection succinylcholine $1.5 \mathrm{mg} / \mathrm{kg}$ following which endotracheal intubation was done with portex cuffed endotracheal tube no 8. After confirmation of placement of endotracheal tube, ventilation was maintained with $\mathrm{O}_{2}+\mathrm{N}_{2} \mathrm{O}$ (50:50) and sevoflurane at a minimum alveolar concentration of 1.5. Patient was given injection rocuronium $1.2 \mathrm{mg} /$ $\mathrm{kg}$. Patient's eyes were taped, all pressure points were padded, and patient was given a prone position.

Air entry was checked again in prone position. His pulse was $46 / \mathrm{min}$, regular, and BP was $80 / 60 \mathrm{~mm} \mathrm{Hg}$.

After cleaning and draping the patient's back, the orthopedic surgeon located the spinal level by a $16 \mathrm{G}$ intravenous (IV) cannula, which was repeated two to three times. Suddenly, patient went into bradycardia (pulse 40 beats per minute) and his BP measured 70/40 $\mathrm{mm} \mathrm{Hg}$. His carotids were palpable. Injection atropine 0.1 $\mathrm{mg}$ and injection mephentermine $(12+12+6 \mathrm{mg})$ were administered, and patient was immediately made supine from prone position.

No response to atropine was observed, so IV atropine $0.1 \mathrm{mg}$ was repeated. Patient went into cardiac arrest (pulseless electrical activity). Cardiac compressions were started immediately, and injection adrenaline $1 \mathrm{mg}$ was given. Patient could be revived successfully after 1 minute following cardiopulmonary cerebral resuscitation. Patient was kept intubated and right-sided internal jugular vein was cannulated with a triple-lumen 7 French ( Fr) central line.

After the effect of IV adrenaline wore off, patient's BP continued to remain low, in the range of 60 to 70 systolic and 35 to 45 diastolic. His pulse rate remained 


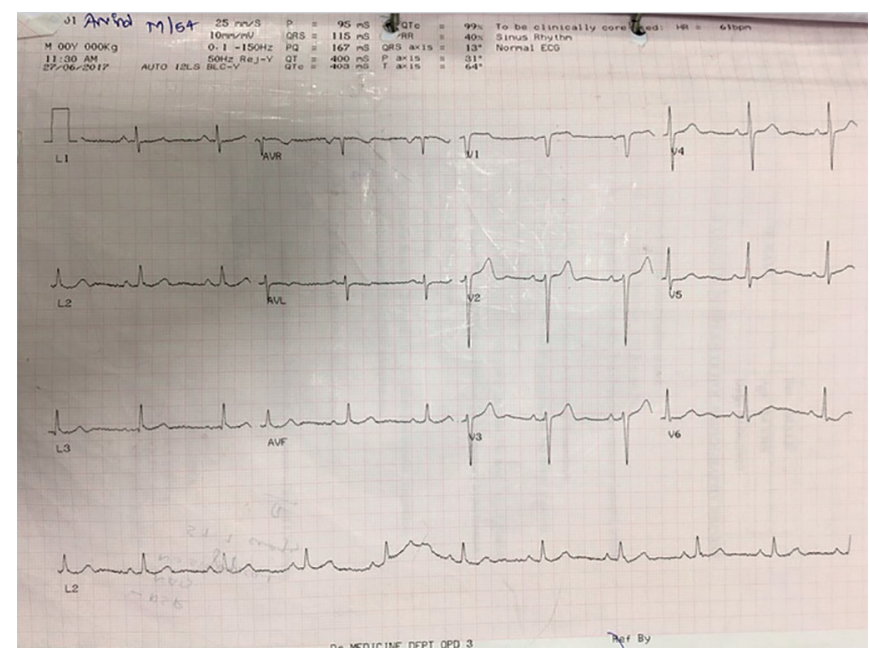

Fig. 1: Preoperative electrocardiogram

around 45 to $50 / \mathrm{min}$, irregular, with bradyarrhythmias and junctional rhythms. Patient was put on inotropic support. Injection dopamine was started @ $15 \mu \mathrm{g} / \mathrm{kg} / \mathrm{min}$ and injection adrenaline was started @ $0.1 \mu \mathrm{g} / \mathrm{kg} / \mathrm{min}$. Blood sugar was within normal limits.

It was later discovered that the patient had received an additional dose of his antihypertensive the previous night.

Troponin T was negative.

We suspected the patient had a BB and CCB overdose. Patient required inotropic support for 24 hours and was gradually weaned off the supports and extubated.

A cardiologist's opinion was taken, and patient was started on dual antiplatelet therapy as a prophylaxis. Patient was advised a fresh two-dimensional (2D) Echo and a coronary angiography (CAG) to rule out coronary artery disease.

Patient's 2D Echo was within normal limits. Patient did not give consent for a CAG. He was advised a pacemaker for his sinus arrhythmias.

\section{DISCUSSION}

The importance of a thorough history taking in a preanesthetic evaluation has been emphasized time and again. The preoperative vital parameters of our patient were stable, and the patient did not complain of dizziness / palpitations, which are often associated with SSS (Fig. 1). ${ }^{4}$

The SSS is characterized by sinus node dysfunction with an atrial rate inappropriate for physiologic requirements because the sinus node is unable to perform its pacemaking function (Figs 2 and 3). 1,2,5

The combination of $\mathrm{CCB}$ and $\mathrm{BB}$ is increasingly used in the management of hypertension. Anesthesia can cause myocardial depression in patients on $\mathrm{BB}^{2}$ and silent myocardial ischemia in those on $\mathrm{CCB}{ }^{6}$ However, the effect of anesthesia on patients receiving

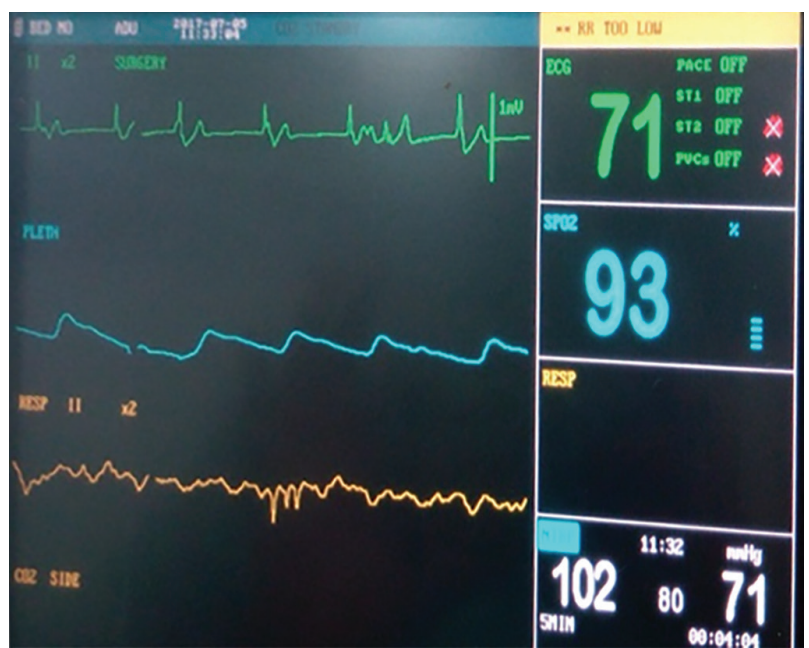

Fig. 2: Intraoperative electrocardiogram with junctional rhythm

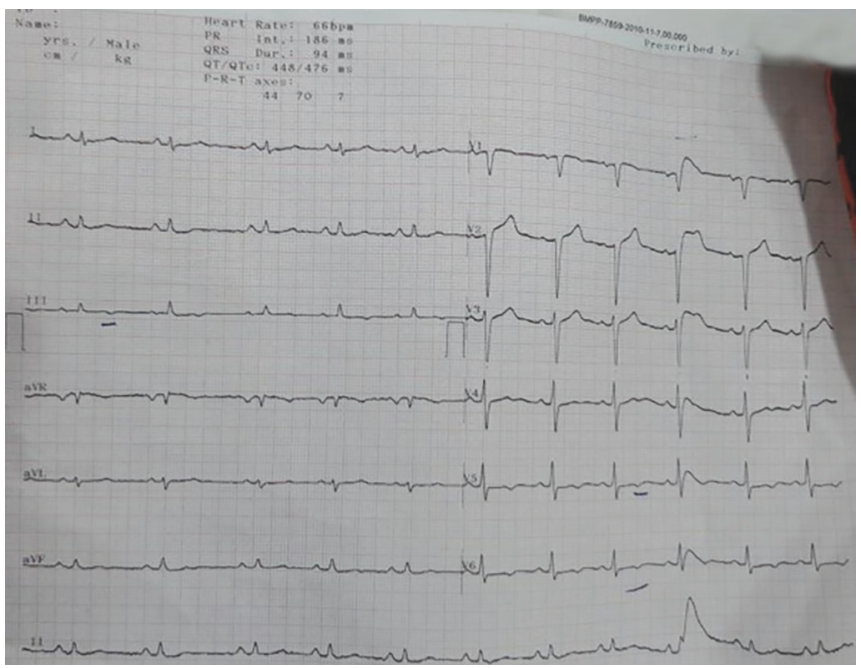

Fig. 3: Postoperative electrocardiogram after 24 hours

a combination of $\mathrm{CCB}$ and $\mathrm{BB}$ is unique and was studied by Samad et al, ${ }^{7}$ who found that hypotension (systolic BP $<90 \mathrm{~mm} \mathrm{Hg}$ ) and bradycardia ( $\mathrm{HR}<50 / \mathrm{min}$ ) were more common in CCB and BB group (55\%) than in BB group $(15 \%)$ alone. Our patient was receiving a combination of $\mathrm{BB}$ and $\mathrm{CCB}$.

The shock resulting from BB and CCB toxicity can be very resistant despite the use of all available catecholamines for resuscitation. ${ }^{3}$ Predictably, our patient needed a high dose of IV dopamine and IV adrenaline infusion for treating his hypotension and bradycardia. The IV fentanyl given as a premedication aggravated the bradycardia of the patient. A thorough history is of utmost importance not only in the preanesthetic checkup, but also in the immediate perioperative period.

Traditionally, BB toxicity was treated with glucagon and $\mathrm{CCB}$ with calcium gluconate infusion. ${ }^{8}$ However, glucagon was not available in our institution and our patient was maintaining vitals on high dose of inotropic support. 


\section{CONCLUSION}

Profound and refractory hypotension can be encountered in hypertensive patients on chronic BB and CCB therapy in the absence of toxic levels. We have described our management of this case of a suspected SSS, who required a high dose of inotropic support of injection dopamine and injection adrenaline to maintain his pulse rate and BP. Also, a thorough history from the patient's relative led us to arrive at a conclusion of an overdose of $\mathrm{BB}$ and $\mathrm{CCB}$, leading to an SSS-like situation.

\section{REFERENCES}

1. Adan V, Crown LA. Diagnosis and treatment of sick sinus syndrome. Am Fam Physician 2003 Apr;67(8):1725-1732.

2. Mangrum JM, Dimarco JP. The evaluation and management of bradycardia. N Engl J Med 2000 Mar;342(10):703-709.
3. Kerns W 2nd. Management of beta-adrenergic blocker and calcium channel antagonist toxicity. Emerg Med Clin North Am 2007 May;25(2):309-331.

4. Irené Ferrer M. The sick sinus syndrome. Circulation 1973 Mar;47:635-641.

5. Rodriguez RD, Schocken DD. Update on sick sinus syndrome, a cardiac disorder of aging. Geriatrics 1990 Jan;45(1): 26-30.

6. Sear JW, Foex P, Howell SJ. Effect of chronic intercurrent medication with beta-adrenoceptor blockade or calcium channel entry blockade on postoperative silent myocardial ischaemia. Br J Anaesth 2000 Mar;84(3):311-315.

7. Samad K, Khan F, Azam I. Hemodynamic effects of anesthetic induction in patients treated with beta and calcium channel blockers. Middle East J Anaesthesiol 2008 Jun;19(5): 1111-1128.

8. Shepherd G. Treatment of poisoning caused by beta-adrenergic and calcium-channel blockers. Am J Health Syst Pharm 2006 Oct;63(19):1828-1835. 